\title{
Ischemic Colitis: Characteristics and Predictive Factors of Severity, in Hospital Mortality and Relapse ${ }^{\S}$
}

\author{
J. Cubiella Fernández ${ }^{*}, 1$, L. Núñez Calvo ${ }^{2}$, E. González Vázquez ${ }^{3}$, M. Vega García-Luengos ${ }^{1}$ and \\ J. Fernández Seara ${ }^{1}$
}

\author{
Departments of ${ }^{1}$ Gastroenterology and ${ }^{2}$ Internal Medicine, Complexo Hospitalario de Ourense, Internal Medicine, \\ ${ }^{3}$ Fundación Pública Hospitalaria de Verin, Ourense, Spain
}

\begin{abstract}
Objective: The study was designed to describe a cohort of patients with ischemic colitis (I.C.) that required admission and the factors related to severity and mortality. Also, we tried to define the risk of relapse after discharge and the variables associated.

Methods: Descriptive and retrospective study of patients with I.C. diagnosed between January 1996 and March 2003. Qualitative variables were analyzed using Fisher exact test and parametric variables were analyzed using Student's t-test. Those variables statistically significant were included in a Cox regression model.

Results: During the study period, 169 patients with I.C. were admitted into hospital. Ten patients required surgery, 8 patients died and 13 were considered severe. The variables independently associated to severity were: cerebrovascular disease (OR: 6.63, 95\% CI: 1.59-27.61, p: 0.009), absence of hematochezia (OR: 4.43, 95\% CI: 1.12-17.47, p: 0.033), abdominal distention (OR 6.39, 95\% CI: 1.65-24.70, p: 0.007) and ileus (OR 8.76, 95\% CI: 2.12-36.06, p: 0.003). Only diffuse peritonism was associated to mortality (OR: 26.07, 95\% CI: 5.67-119.93, p<0.001). After discharge, seven (4.5\%) patients had a relapse (mean time: 5.31t3.67 months), with a stricture in 6 of them. A second episode of I.C. (OR: 13.21, 95\% CI: 2.52-69.28, p: 0.002), treatment with aspirin (OR 6.41, 95\% CI: 1.12-36.64, p: 0.037) and with antihypertensive drugs (OR 0.089, 95\% CI: 0.01-0.754, p: 0.027) were independently associated to relapse.

Conclusions: We identified several predictive factors that can be used to stratify patients on admission. We found a relation between treatment with aspirin, antihypertensive drugs and relapse that should be confirmed in prospective studies.
\end{abstract}

Keywords: Ischemic colitis, cerebrovascular disorders, hematochezia, peritonism, aspirin, antihypertensive agents.

\section{INTRODUCTION}

Ischemic colitis (I.C.) is generally considered to be a disease of the elderly as a consequence of insufficient blood supply for the requirements of the large intestine. I.C. is the most common form of ischemic injury to the gastrointestinal tract and the second most common cause of lower gastrointestinal bleeding $[1,2]$. Many different factors have been associated with I.C. such as decreased cardiac output or arrhythmia, trauma, drugs, surgery, vasculitis, and coagulation disorders [1]. However, the disorder usually develops in the absence of major vessel occlusion and the cause is not clearly defined in most cases [3].

Clinical presentation varies from mild and limited forms not needing medical treatment to fulminant trans-mural

*Address correspondence to this author at the Servicio de Aparato Digestivo, Complexo Hospitalario de Ourense, Rua Ramón Puga 52-54, 32003 Ourense, Spain; Tel: 988385715; Fax: 988385518;

E-mail: joaquin.cubiella.fernandez@sergas.es

${ }^{\S}$ Meeting Presentation:

VIII Congreso de la Asociación Española de Gastroenterología, Madrid, 1012 March 2005.

$13^{\text {th }}$ United European Gastroenterology Week "UEGW 2005", Copenhagen, Denmark, 15-19 October 2005.

$16^{\text {th }}$ United European Gastroenterology Week "UEGW 2008" Vienna, 18-22 October 2008. colonic necrosis that require surgery and may lead to death [3]. The clinical presentation varies according to severity, extent, and rapidity of the ischemic insult, resistance of the bowel wall to hypoxia, and its intrinsic ability to protect itself against bacterial invasion. The possibility of establishing prognostic factors promptly is of a great importance to decide the best therapeutic approach for each case. However, there are only a few studies available on the relation of etiological, pathogenic and clinical factors to I.C. outcome [4$10]$.

In general, transient I.C. is followed by a complete structural and functional recovery within one or two weeks. However, chronic damage, in the form of persistent segmental colitis and strictures, has been described to occur in up to 20 to 25 percent and 10 to 15 percent of patients, respectively [3]. However, recent studies have found clinical recurrence to be less frequent than previously described $[8,9]$. Furthermore, there is no study evaluating the prognostic factors related to relapse.

The purpose of our study was to review the clinical, endoscopic and histologic characteristics of patients admitted into our hospital with I.C. and to identify those factors associated with severity and mortality. We also tried to define the risk of relapse after discharge, and those factors associated to recurrence. 


\section{PATIENTS AND METHODS}

\section{Study Design}

Descriptive and retrospective study based on review of medical records.

\section{Patients}

We have reviewed all the endoscopic and histologic reports with the diagnosis of colitis between January 1996 and March 2003 in our hospital. Patients with a diagnosis of antibiotic associated colitis, inflammatory bowel disease, diverticulitis or infectious colitis were excluded. The diagnosis of I.C. was based on the endoscopic findings with a definitive or compatible histology. A definitive histology was considered when mucosal infarctation, thrombus or fibrin in the capillaries or submucosal hemorrhage was found. Instead, a compatible histology was diagnosed when loss of mucin and surface epithelial cells. a mild to moderate inflammatory cell infiltrate, edema or vascular congestion was present $[3,11,12]$. Whenever a colonoscopy was not available, diagnosis was based on surgical specimen. Those patients with the diagnosis of I.C. that did not require admission were also excluded. Finally, we included 169 patients with the diagnosis of I.C. that required admission into our hospital. Complexo Hospitalario de Ourense is a second level hospital in the Servicio Gallego de Salud, the public health system of Galicia-Spain, and attends 340.000 inhabitants.

\section{Descriptive Analysis}

Clinical variables including age, sex, time elapsed from the onset of symptoms to admission, personal medical history (mainly cardiovascular) and regular medications were analyzed. Symptoms, physical signs and biochemical parameters on admission were evaluated. When a colonoscopy was performed the type and location of endoscopic findings were collected. Histologic findings were analyzed as well. Medical and surgical treatment, including fasting period, antibiotics, analgesia, anticoagulants, surgery, complications, time to discharge, were reviewed. Finally, complications, inhospital mortality and time to discharge were also collected. Continuous variables were expressed as mean \pm standard deviation. Qualitative variables were expressed as absolute number and percentage.

\section{Severity Prognostic Factors}

As previously described in other studies, we defined a moderate or mild group and a severe or complicated group [8-10, 13]. Severe I.C. included those patients that required surgery or died during admission. In contrast, mild I.C. included those patients that did not require surgery and had a good evolution only with medical treatment. To detect any possible relationship between the different variables obtained on admission and severe I.C. an univariant statistical analysis was performed. We used the Fisher exact test in qualitative variables and the Student's t test in parametric variables. Finally all statistically significant variables were included into a Cox regression model (forward stepwise), in order to detect those independently related to severity. The results were expressed as Odds Ratio and confidence interval. We considered statistically significant those differences with $\mathrm{p}$ $<0.05$.

\section{Inhospital Mortality Prognostic Factors}

To detect any possible relationship between the different variables measured on admission and mortality an univariant statistical analysis was performed. All statistically significant or clinically relevant variables were included into a Cox regression model (forward stepwise), to detect those independently related to mortality. The results were expressed as Odds Ratio and confidence interval. We considered statistically significant those differences with $\mathrm{p}<0.05$.

\section{Relapse After Discharge}

After discharge, the last follow-up date, the patient's condition and relapses were collected from medical records. If a relapse was diagnosed, the symptoms, the way to diagnosis, the presence of stenosis and the treatment provided were analyzed. Variables regarding demographics, personal medical history, regular medications. endoscopic findings and inhospital treatments were analyzed. Survival curves were generated according to the Kaplan Meier method and univariate survival distributions were compared with the use of the log-rank test. Finally, all statistically significant or clinically relevant variables were included into Cox regression model (forward stepwise), to detect those independently related to relapse. We considered statistically significant those differences with $\mathrm{p}<0.05$.

The statistical calculations were performed using SPSS 10.0 .

\section{RESULTS}

\section{Descriptive Analysis}

The data regarding age, sex, personal medical history, regular medications, symptoms and physical findings at the time of admission are shown in Table 1. The time elapsed from the onset of symptoms was $3.2 \pm 6.1$ days. The biological, haematological and biochemical parameters obtained on admission are expressed in Table 2. The diagnosis of I.C. was based on colonoscopy findings in 159 patients. The length of the colon affected was $32.71 \pm 18.18 \mathrm{~cm}$. The endoscopic locations are expressed in Fig. (1) and the endoscopic findings are shown in Fig. (2). Histologic findings are expressed in Fig. (3).

With regard to evolution during admission, the average stay was of $11.2 \pm 10.55$ days, with a diagnosis delay of 4.62 \pm 4.34 days and a fasting time of $3.49 \pm 6.76$ days. 60 patients $(36.6 \%)$ received antibiotic treatment, analgesia was administered to 54 patients (33.1\%) and 25 patients (15.2\%) received anticoagulant therapy. Surgery was performed in 10 patients (5.9\%): 4 due to acute abdomen at the time of admission, 6 due to deterioration despite medical treatment. $50 \%$ out of these patients that required surgery, died during hospitalization. 12 patients (7.1\%) had some kind of complication. Finally, 8 patients $(4.6 \%)$ died during admission, been the cause of death directly related to I.C in seven of them. The mean time to death was $12.25 \pm 13.24$ days. The group of severe I.C. (6.77 \pm 11.68 days) comprised thirteen patients $(7.7 \%)$ : ten required surgery and eight died during admission. 
Table 1. Clinical Characteristics of Patients with I.C. and Predictive Factors of Severity by Univariant Analysis

\begin{tabular}{|c|c|c|c|c|}
\hline & All & Mild I.C. & Severe I.C. & $\mathbf{P}$ \\
\hline - $\quad$ Age (years) & $75.73 \pm 10.5$ & $75.43 \pm 10,50$ & $79.28 \pm 10.34$ & 0.165 \\
\hline - $\operatorname{Sex}(M / F)$ & $74 / 95$ & $67 / 89$ & $7 / 6$ & 0.317 \\
\hline \multicolumn{5}{|l|}{ Personal medical history } \\
\hline - Arterial hypertension (yes) & $97(57.4 \%)$ & $87(55.8 \%)$ & $10(76.9 \%)$ & 0.116 \\
\hline - Dislypemia (yes) & $44(26 \%)$ & $41(26.3 \%)$ & $3(23.1 \%)$ & 0.548 \\
\hline - Diabetes mellitus (yes) & $33(19.5 \%)$ & $30(19.2 \%)$ & $3(23.1 \%)$ & 0.485 \\
\hline - Smoking habit (yes) & $17(10.1 \%)$ & $15(9.6 \%)$ & $2(15.4 \%)$ & 0.385 \\
\hline - Chronic renal failure (yes) & $7(4.1 \%)$ & $6(3.8 \%)$ & $1(7.7 \%)$ & 0.435 \\
\hline - Valve heart disease (yes) & $12(7.1 \%)$ & $11(7.1 \%)$ & $1(7.7 \%)$ & 0.630 \\
\hline - Ischemic heart disease (yes) & $31(18.3 \%)$ & $27(17.3 \%)$ & $4(30.8 \%)$ & 0.196 \\
\hline - Hypertensive heart disease (yes) & $26(15.4 \%)$ & $23(14.7 \%)$ & $3(23.1 \%)$ & 0.321 \\
\hline - $\quad$ Atrial fibrillation (yes) & $25(14.8 \%)$ & $20(12.8 \%)$ & $5(38.5 \%)$ & 0.027 \\
\hline - Peripheral arteriopathy (yes) & $13(7.7 \%)$ & $10(6.4 \%)$ & $3(23.1 \%)$ & 0.065 \\
\hline - Abdominal aorta surgery (yes) & $2(1.2 \%)$ & 0 & $2(15.4 \%)$ & 0.005 \\
\hline - Ischemic colitis (yes) & $7(4.1 \%)$ & $7(4.3 \%)$ & 0 & 0.708 \\
\hline - Shock (yes) & $7(4.1 \%)$ & $4(2.6 \%)$ & $3(23.1 \%)$ & 0.011 \\
\hline - Cerebrovascular disease (yes) & $21(12.4 \%)$ & $15(9.6 \%)$ & $6(46.2 \%)$ & 0.002 \\
\hline \multicolumn{5}{|l|}{ Medications } \\
\hline - Acetylsalicylic acid (yes) & $54(32 \%)$ & $49(31.4 \%)$ & $5(38.5 \%)$ & 0.404 \\
\hline - $\quad$ NSAIDs (yes) & $18(10.7 \%)$ & $16(10.3 \%)$ & $2(15.4 \%)$ & 0.414 \\
\hline - Acenocumarol (yes) & $10(5.9 \%)$ & $9(5.8 \%)$ & $1(7.7 \%)$ & 0.561 \\
\hline - Low weight heparin (yes) & $3(1.8 \%)$ & $2(1.3 \%)$ & $1(7.7 \%)$ & 0.215 \\
\hline - Digoxine (yes) & $6(3.6 \%)$ & $5(3.2 \%)$ & $1(7.7 \%)$ & 0.386 \\
\hline - Diuretics (yes) & $35(20.7 \%)$ & $31(19.9 \%)$ & $4(30.8 \%)$ & 0.270 \\
\hline - Antidepressants (yes) & $6(3.6 \%)$ & $6(3.8 \%)$ & 0 & 0.614 \\
\hline - Antihypertensives (yes) & $91(53.8 \%)$ & $86(55.1 \%)$ & $5(38.5 \%)$ & 0.193 \\
\hline \multicolumn{5}{|c|}{ Symptoms and Physical Findings on Admission } \\
\hline - Abdominal pain (yes) & $137(82 \%)$ & $129(83.8 \%)$ & $8(61.5 \%)$ & 0.060 \\
\hline - Hematochezia (yes) & $154(91.1 \%)$ & $147(94.2 \%)$ & $7(53.8 \%)$ & $<0.001$ \\
\hline - Diarrhea (yes) & $119(70.4 \%)$ & $113(72.4 \%)$ & $6(46.2 \%)$ & 0.051 \\
\hline - $\quad$ Fever (yes) & $22(13 \%)$ & $18(11.5 \%)$ & $4(30.8 \%)$ & 0.070 \\
\hline - Abdominal distention (yes) & $12(7.2 \%)$ & $6(3.9 \%)$ & $6(50 \%)$ & $<0.001$ \\
\hline - Vomit (yes) & $48(28.4 \%)$ & $43(27.7 \%)$ & $5(38.5 \%)$ & 0.298 \\
\hline - Localizad peritonism (yes) & $8(4.7 \%)$ & $6(3.8 \%)$ & $2(16.7 \%)$ & 0.103 \\
\hline - Diffuse peritonism (yes) & $7(4.2 \%)$ & $2(1.3 \%)$ & $5(41.7 \%)$ & $<0.001$ \\
\hline - Ileus (yes) & $15(8.9 \%)$ & $11(7.1 \%)$ & $4(33.3 \%)$ & 0.014 \\
\hline
\end{tabular}

Parametric variables are expressed as mean \pm SD. Qualitative variables are expressed in as absolute numbers and percentages. Differences were considered statistically significant when $\mathrm{p}<0.05$. 
Table 2. Physical, Biochemical and Haematological Data on Admission and Predictive Factors of Severity by Univariant Analysis

\begin{tabular}{|c|c|c|c|c|}
\hline & All & Mild I.C. & Severe I.C. & $\mathbf{P}$ \\
\hline - Sistolic arterial pressure $(\mathrm{mmHg})$ & $137.75 \pm 26.41$ & $139.33 \pm 25.57$ & $118.85 \pm 30.01$ & 0.007 \\
\hline - Diastolic arterial pressure (mmHg) & $76.33 \pm 13.77$ & $77.37 \pm 12.83$ & $63.85 \pm 18.61$ & 0.001 \\
\hline - Heart rate (beats/minute) & $78.7 \pm 14.44$ & $78.09 \pm 13.07$ & $89.67 \pm 28.11$ & 0.019 \\
\hline - Temperature $\left({ }^{\circ} \mathrm{C}\right)$ & $36.54 \pm 0.65$ & $36.51 \pm 0.63$ & $36.9 \pm 0.82$ & 0.045 \\
\hline - Leukocyts (mil/mm³) & $11.84 \pm 8.4$ & $11.76 \pm 8.6$ & $12.78 \pm 6.1$ & 0.676 \\
\hline - Haemoglobin (gr/dl) & $13.28 \pm 1.97$ & $13.40 \pm 1.96$ & $11.86 \pm 1.57$ & 0.006 \\
\hline - Platelets $\left(\mathrm{mil} / \mathrm{mm}^{3}\right)$ & $223.1 \pm 78.35$ & $222.95 \pm 79.22$ & $225.87 \pm 62.42$ & 0.903 \\
\hline - I.N.R & $1.26 \pm 0.59$ & $1.25 \pm 0.61$ & $1.35 \pm 0.43$ & 0.571 \\
\hline - Protrombine time $(\%)$ & $82.28 \pm 18.24$ & $82.93 \pm 18.30$ & $74.65 \pm 16.26$ & 0.116 \\
\hline - Glucose (mg/dl) & $127.28 \pm 47.11$ & $125.89 \pm 48.28$ & $143.62 \pm 26.17$ & 0.194 \\
\hline - Urea (mg/dl) & $59.98 \pm 51.31$ & $58.19 \pm 52.42$ & $81.38 \pm 28.93$ & 0.118 \\
\hline - Creatinine (mg/dl) & $1.23 \pm 1.03$ & $1.21 \pm 1.07$ & $1.38 \pm 0.48$ & 0.873 \\
\hline - Sodium (mEq/l) & $138.22 \pm 3.63$ & $138.32 \pm 3.7$ & $137.31 \pm 2.46$ & 0.337 \\
\hline - Potasium (mEq/l) & $4.25 \pm 0.61$ & $4.22 \pm 0.58$ & $4.62 \pm 0.93$ & 0.023 \\
\hline - Calcium (mg/dl) & $8.72 \pm 0.62$ & $8.78 \pm 0.57$ & $7.88 \pm 0.93$ & $<0.001$ \\
\hline - $\quad$ LDH (I.U./I) & $382.07 \pm 196.04$ & $372.63 \pm 180.61$ & $698.50 \pm 504.17$ & 0.02 \\
\hline - $\mathrm{pH}$ & $7.38 \pm 0.06$ & $7.38 \pm 0.06$ & $7.41 \pm 0.05$ & 0.286 \\
\hline - $\mathrm{HCO}_{3}(\mathrm{mmol} / \mathrm{l})$ & $24.78 \pm 4.93$ & $25.33 \pm 4.16$ & $21.12 \pm 7.3$ & 0.048 \\
\hline - $\mathrm{PCO}_{2}(\mathrm{~mm} \mathrm{Hg})$ & $40.84 \pm 9.26$ & $42.17 \pm 7.89$ & $36.63 \pm 12.17$ & 0.084 \\
\hline
\end{tabular}

Results are expressed as mean \pm SD. Differences were considered statistically significant when $p<0.05$.

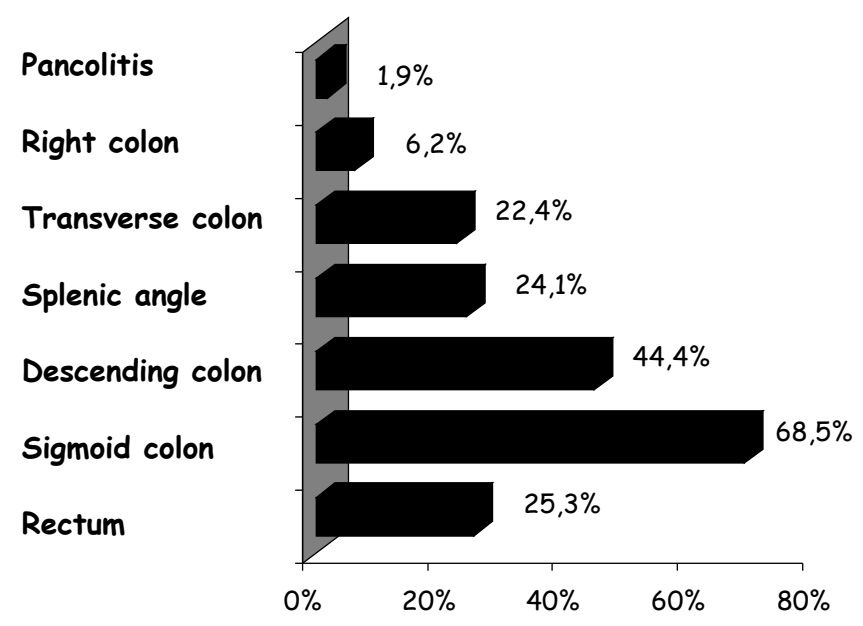

Fig. (1). Endoscopic locations of I.C. The results are expressed as a percentage of total number of colonoscopies.

\section{Severity Prognostic Factors}

The group of severe I.C. (6.77 \pm 11.68 days) comprised thirteen patients $(7.7 \%)$ : ten required surgery and eight died during admission. Data obtained from the univariant analysis are expressed on Tables $\mathbf{1}$ and $\mathbf{2}$. After introducing the statistically significant variables in the univariant analysis into a Cox regression model, the personal history of cerebrovascular disease (OR: 6.63, 95\% I.C: 1.59-27.61, p: 0.009), the absence of hematochezia (OR: 4.43, 95\% I.C: 1.12-17.47,
Hyperemia

Petechiae

Intramucosal bleeding

Fibrin

Ulcers

Active bleeding

Necrosis

Stricture

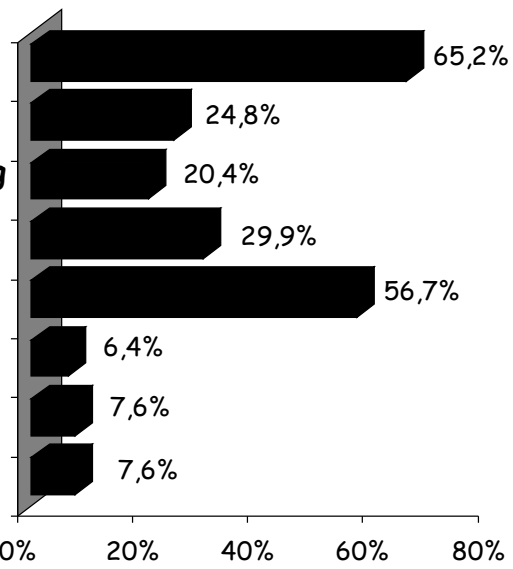

Fig. (2). Endoscopic findings. The results are expressed as a percentage of total number of colonoscopies.

p: 0.033), the presence of abdominal distention (OR 6.39, 95\% I.C: 1.65-24.70, p: 0.007) and ileus (OR 8.76, 95\% I.C: $2.12-36.06$, p: 0.003$)$ were independently associated to severity.

\section{Inhospital Mortality Prognostic Factors}

In the univariant analysis it was found an statistically significant relation between mortality. personal history of vascular cerebral disease ( $\mathrm{p}$ : 0.009), absence of hematoquecia ( $\mathrm{p}$ : 0.002), presence of abdominal distention $(\mathrm{p}<$ $0.001)$, presence of diffuse peritonism $(\mathrm{p}<0.001)$, decreased 


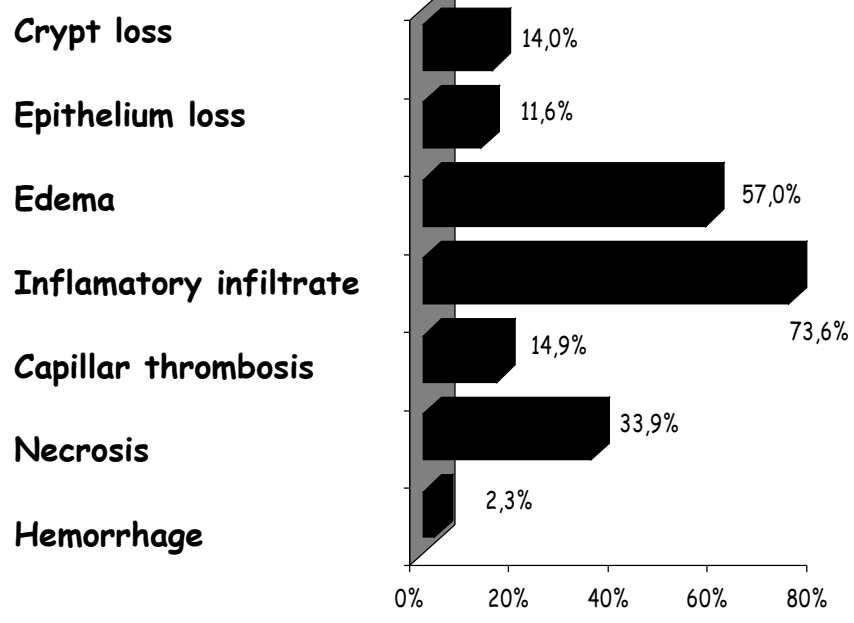

Fig. (3). Histologic Findings. The descriptive results are expressed as a percentage.

serum levels of calcium $(\mathrm{p}<0.001)$ and increased levels of LDH $(\mathrm{p}<0.001)$. After introducing these variables into a Cox regression model, only the presence of diffuse peritonism (OR: 26.07, 95\% I.C: 5.67-119.93, p< 0.001) was independently associated to mortality.

\section{Relapse After Discharge}

Due to lack of follow-up, 6 patients were excluded from the 161 patients discharged alive. The cohort of 155 patients was followed at our centre for a median time of 68.3 months (1-124). 47 patients (30.3\%) died at the end of follow-up. During this interval I.C. relapse was detected in 7 patients. The mean time to diagnosis was $5.31 \pm 3.67$ months. The symptoms at diagnosis were diarrhea [5], abdominal pain [3] and rectal bleeding [3]. A colonic stricture was detected in six patients. Nevertheless, all patients were treated conservatively. In the Kaplan-Meier survival analysis we found a relation statistically significant between the probability of relapse and a previous episode of I.C. continuous treatment with acetyl salicylic, continuous treatment with antihypertensive drugs and presence of edema on histology (Fig. 4). After introducing these variables into a Cox regression model, a previous episode of I.C. (OR: 13.21, 95\% I.C: $2.52-$ 69.28 , p. 0.002 ), continuous treatment with acetyl salicylic acid (OR 6.41, 95\% I.C: 1.12-36.64, p: 0.037) and continuous treatment with antihypertensive drugs (OR 0.089, 95\% I.C: $0.01-0.754$, p: 0.027) were independently associated with relapse of I.C.

\section{DISCUSSION}

In our series, patients that required admission due to I.C. were old. They had a high prevalence of cardiovascular risk factors as well as consumption of antihypertensive drugs, aspirin and diuretics. No prospective study has established the association between I.C. and cardiovascular pathology, chronic obstructive pulmonary disease, use of different medications and other circumstances responsible for a reduction in blood flow. However, observational and metaanalysis studies that point to a relationship between I.C. and irritable bowel syndrome and their treatment with antagonists of 5-HT3 receptors have recently been published [14]. Whether they are different stages of the same process remains unclear. Another predisposing factor for I.C. may be constipation, probably due to the increased colonic luminal pressure which could generate a reduction in blood flow in the colonic wall [4]. Considering that our study was retrospective, these variables could not be collected and their relation with the development of I.C. should be addressed in a specifically designed study.

The spontaneous and usually self-limiting form of I.C. gets in contrast with the fulminant or severe form. The rate of symptomatic self-resolution varies widely from medical to surgical experiences. In medical series, the immediate course was uneventful -did not require surgery and were alive at discharge- in $85.5-66 \%$ of patients $[5,8,10,15]$. In contrast, in surgical experiences, this rate was around $33-50 \%$ [7, 9, 16]. As some mild I.C. can be misdiagnosed, it is difficult to determine the true incidence of I.C. A strict definition of I.C. would require biopsy confirmation of each diagnosis, although, in clinical practice, the criteria used to make an I.C. diagnosis are likely to vary. In fact, most of mild I.C. lack of a definitive histologic criteria, and diagnosis is based on clinical and endoscopic findings with a compatible biopsy. Even when the diagnosis is clinically suspected, and then confirmed by endoscopy and biopsy, finding these cases in an administrative or medical record database depend on an appropriate coding for this diagnosis. In our series, we reviewed our hospital endoscopic and histopathologic reports in order to identify all the patients with the diagnosis of I.C., and consequently it reflects quite accurately the spectrum of the disease in our area. In fact, our severe I.C. incidence is low but similar to that described in a recently prospective study in Spain [15].

In our series, we have determined which factors are associated to severity and inhospital mortality. We have only analyzed those variables available on admission, in order to detect those that could help us to stratify risks when patients arrive to hospital. Out of all the clinical parameters evaluated in our patients, abscense of hematochezia, presence of abdominal distension and ileus predict worse prognosis. These clinical findings may be related to a reduced peristaltism due to trans-mural injury, which could lead to perforation and subsequent peritonitis. Although diffuse peritonism is not independently related to severity, it is noteworthy that is the only prognostic factor of inhospital mortality. These variables are consistent with what has previously been described $[9,10]$. We found no relationship between age and sex, and the subsequent evolution of IC as other studies did $[5,9,16$, 17].

The precise endoscopic and histologic picture of I.C. depends on the rate of the ischemic insult and on the stage of the natural history of the disease at the moment of diagnosis. The initial diagnostic study should be obtained early in the course. Endoscopic findings such as bluish-black mucosa, submucosa hemorrhage, diffuse mucosal edema and intraluminal bleeding are more often detected on early endoscopy [4]. However, caution is indicated when performing colonoscopy. Distention of the bowel could diminishes colonic blood flow and actually may cause or amplify the magnitude of colonic ischemia [3]. Other non specific findings, such as erythema, edema and ulcerations do not correlate with the timing of endoscopy [4]. In our series, the median delay of colonoscopy was four days, and most of the endoscopic findings were non specific and related to limited I.C. 

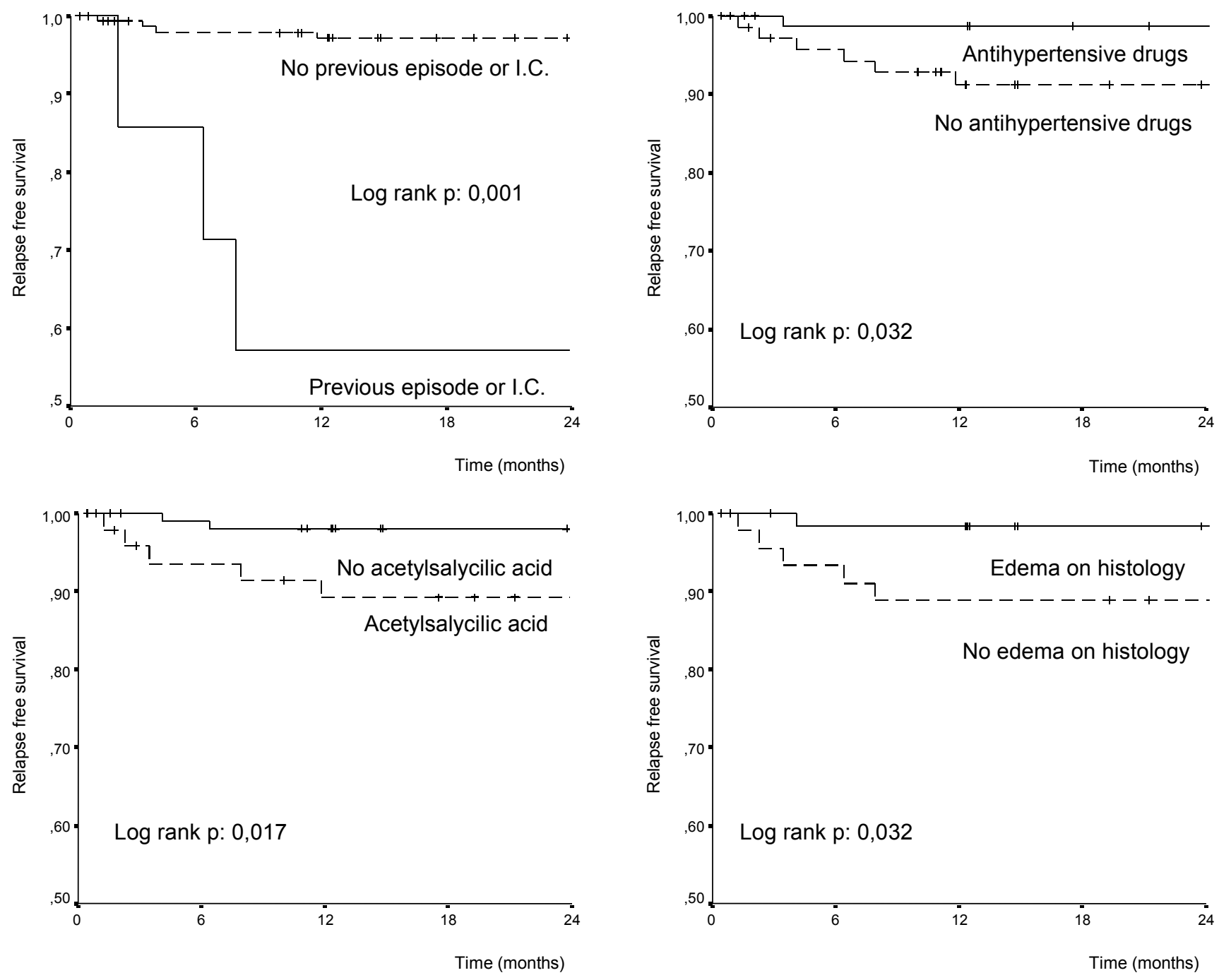

Fig. (4). Relapse free survival according to previous episodes of I.C., treatment with antihypertensive drugs, treatment with acetylsalicylic acid and edema on histology.

Although severe I.C. may benefit from fasting, intravenous fluids, correction of predisposing factors and broad spectrum antibiotics, the rule of theses treatments is doubtful in mild I.C. In fact, mild I.C can be managed as outpatient if endoscopy excludes necrosis and patient tolerates diet. The role of antibiotics is unclear. In experimental studies, antibiotics have demonstrated to offer protection against bacterial translocation [18] and prolong survival after intestinal ischemia in rats [19]. In fact, its common use is recommended by many authors [3, 20]. However, there is no clinical evidence of beneficial effects, and this issue should be addressed in a prospective randomized trial. In our series, many patients received antibiotics, not only in the severe group but also in the mild one.

In some cases, mild I.C. can evolve to a chronic form. In these cases damage penetrates the muscularis propria. The damaged muscularis is replaced by fibrous tissue during a period of weeks to months and frequently results in a colonic stricture. In addition, granulation tissue may replace the injured mucosa and submucosa, and eventually, as mucosa regenerates over the edematous and widened submucosa, chronic ulcerations and persistent areas of segmental colitis develop [3, 12]. However, there is little information on the evolution of I.C. after discharge and the risk of relapse. Two recent studies have addressed this question. Hugier et al. [9] described 5 recurrences of the 58 patients who survived the initial episode of I.C. One had a fatal course due to recurrence and died. Medina et al. [8] found 5 relapse out of 48 patients who were discharged. In this series, all patients developed a stricture, but were managed in a conservative fashion. Our study shows a low risk of relapse after discharge. All relapses took place in the year after discharge, and were mainly related to the development of strictures. However in all cases the course was benign and did not require surgery.

We have identified three variables independently related to the risk of relapse: treatment with acetyl salicylic acid, use of antihypertensive drugs, a previous episode of I.C and edema on histology. NSAIDs and salycilates have been largely associated to several forms of colitis, including I.C [21-23]. Studies in the TNBS model confirmed the ability of NSAIDs to exacerbate colitis [24]. There is now convincing evidence from animal studies that it is the inhibition of COX-2 by NSAIDs that is responsible of this effect [24]. NSAIDs asso- 
ciated colitis has been associated to both short term [21, 23] and long term treatments [22]. In our series we can not determine if there is any relation between the onset of I.C. and the treatment with acetyl salicylic acid or NSAIDS. COX-2 is also a major contributor to the processes that lead to resolution of inflammation. COX-2-derived PGD2 acts as a "stop signal", reducing granulocyte infiltration [25]. Furthermore, the inhibition of COX-2 and of the prostaglandins with vasodilator effect could increase vascular resistance in splanchnic circulation [23]. These mechanisms could explain the relation between treatment with aspirin and the increased risk of relapse found in our series.

The mechanism for the protective role of antihypertensive drugs is unclear. Angiotensin II (Ang II) is a pro-inflammatory hormone that has been shown to be involved in many pathological conditions. Tissue and plasma levels are increased during stress leading to a release of reactive oxygen species from vascular smooth muscle provoking cellular damage and inflammation. Ang II participates in several key events of the inflammatory response. Colonic mucosal levels of angiotensin I and II are higher in patients with Crohn's disease and correlates with the degree of inflammation [26]. Several drugs that block the effect of angiotensin II have shown a beneficial effect on experimental colitis. Captopril, an angiotensin converting enzyme inhibitor could reduce the levels of Ang II and the colonic fibrosis [27]. Furthermore, two Ang II receptor antagonist, losartan and valsartan have demonstrated an antiinfflamatory effect in colitis [28].

In conclusion, I.C. usually has a benign course after acute colonic insult. We have identified several factors associated to severity and inhospital mortality. These variables could help to stratify patients into high risk and low risk. Furthermore, the risk of relapse seems to be related to treatment with acetyl salicylic acid, antihypertensive drugs and a previous episode of I.C. However, it is necessary to carry out prospective and controlled studies in order to clearly detect the factors that predict the evolution and find the best therapeutic approach.

\section{ACKNOWLEDGEMENTS}

JCF designed the study, performed the statistical analysis and wrote the article. LNC and EGV reviewed the clinical records, produced the database, and reviewed the article. MVG and JFS designed the study and reviewed the article.

\section{REFERENCES}

[1] Sreenarasimhaiah J. Diagnosis and management of intestinal ischemic disorders. BMJ 2003; 326: 1372-6.

[2] Newman JR, Cooper MA. Lower gastrointestinal bleeding and ischemic colitis. Can J Gastroenterol 2002; 16: 597-600.

[3] Gandhi SK, Hanson MM, Vernava AM, et al. Ischemic colitis. Dis Colon Rectum 1996; 39: 88-100.

[4] Habu Y, Tahashi Y, Kiyota K, et al. Reevaluation of clinical features of ischemic colitis. Analysis of 68 consecutive cases diagnosed by early colonoscopy. Scand J Gastroenterol 1996; 31: 8816.
[5] Barouk J, Gournay J, Bernard P, et al. Ischemic colitis in the elderly: predictive factors of gangrenous outcome. Gastroenterol Clin Biol 1999; 23: 470-4

[6] Blanco-Díaz J, Rodríguez-Hermosa JI, Pujadas de Palol M, et al. Ischemic colitis: two forms of clinical presentation and outcome. Cir Esp 2006; 79: 245-9.

[7] Scharff J, Longo WE, Vartanian SM, et al. Ischemic colitis: spectrum of disease and outcome. Surgery 2003; 134: 624-9.

[8] Medina C, Vilaseca J, Videla S, et al. Outcome of patients with ischemic colitis: review of fifty-three cases. Dis Colon Rectum 2004; 47: 180-4.

[9] Huguier M, Barrier A, Boelle PY, et al. Ischemic colitis. Am J Surg 2006; 192: 679-4.

[10] Añón R, Boscá MM, Sanchiz V, et al. Factors predicting poor prognosis in ischemic colitis. World J Gastroenterol 2006; 12: 4875-8.

[11] Bower TC. Ischemic colitis. Surg Clin North Am 1993; 73: 103753.

[12] Price AB. Ischaemic colitis. Curr Top Pathol 1990; 81: 229-46.

[13] Danse EM, Van Beers BE, Jamart J, et al. Prognosis of ischemic colitis: comparison of color Doppler sonography with early clinical and laboratory findings. AJR 2000; 175: 1151-4.

[14] Higgins P, Davis K, Laine L. Systematic review: the epidemiology of ischaemic colitis. Aliment Pharmacol Ther 2004; 19: 729-38.

[15] Montoro MA, Santolaria S.B, Sánchez-Puértolas B, et al. GTECIE Group. Clinical characteristics and outcome of ischemic colitis in Spain. A multicentre and prospective study (ICS study). Gut 2006; 55 (Suppl V): A208.

[16] Longo WE, Ballantyne GH, Gusberg RJ. Ischemic colitis: patterns and prognosis. Dis Colon Rectum 1992; 35: 726-30.

[17] Pla Marti V, Alos Company R, Ruiz Carmona MD, et al. Experience and results on the surgical and medical treatment of ischaemic colitis. Rev Esp Enferm Dig 2001; 93: 501-8.

[18] Plonka AJ, Schentag JJ, Messinger S, et al. Effects of enteral and intravenous antimicrobial treatment on survival following intestinal ischemia in rats. J Surg Res 1989; 46: 216-220.

[19] Redan JA, Rush BF, Lysz TW, et al. Organ distribution of gutderived bacteria caused by bowell manipulation or ischemia. Am J Surg 1990; 159: 85-90.

[20] Bower T.C. Ischemic colitis. Surg Clin North Am 1993; 73: 103753.

[21] Garcia B, Ramaholimihaso F, Diebold MD, et al. Ischaemic colitis in a patient taking meloxicam. Lancet 2001; 357: 690.

[22] Gleeson MH, Davis AJM. Non-steroidal anti-inflammatory drugs, aspirin and newly diagnosed colitis: a case-control study. Aliment Pharmacol Ther 2003; 17: 817-25.

[23] D’Halluin PN, Turlin B, Polard E, et al. Selective COX-2 inhibitor associated colitis: two case reports. Gastroenterol Clin Biol 2003; 27: $932-35$

[24] Ajuebor MN, Singh A, Wallace JL. Cyclooxygenase-2-derived prostaglandin D2 is an early anti-inflammatory signal in experimental colitis. Am J Physiol Gastrointest Liver Physiol 2000; 279: G238-44.

[25] Wallace JK. COX-2: A pivotal enzyme in mucosal protection and resolution of inflammation. Scientific WorldJournal 2006; 6: 57788.

[26] Santiago OI, Rivera E, Ferder L, et al. An angiotensin II receptor antagonist reduces inflammatory parameters in two models of colits. Regul Pept 2008; 146: 250-9.

[27] Wengrower D, Zannineli G, Pappo O, et al. Prevention of fibrosis in experimental colitis by captopril: the role of TGF-beta1. Inflamm Bowel Dis 2004; 10(5): 536-45.

[28] Inokuchi Y, Morohashi T, Kawana I, et al. Amelioration of 2, 4, 6trinitrobenzene sulphonic acid induced colitis in angiotensinogen gene knockout mice. Gut 2005; 54: 349-56. 